\title{
miR-26a inhibits ovarian cancer cell proliferation, migration and invasion by targeting TCF12
}

\author{
SAINAN GAO ${ }^{1 *}$, TINGTING BIAN ${ }^{2 *}$, MIN SU $^{1}$, YIFEI LIU ${ }^{2}$ and YUQUAN ZHANG ${ }^{1}$ \\ Departments of ${ }^{1}$ Obstetrics and Gynecology and ${ }^{2}$ Pathology, \\ Affiliated Hospital of Nantong University, Nantong, Jiangsu 226001, P.R. China
}

Received July 9, 2019; Accepted October 25, 2019

DOI: $10.3892 /$ or.2019.7417

\begin{abstract}
Epithelial ovarian cancer (OC) is a common cause of death from gynecological tumors. MicroRNAs (miRNAs) may function as either oncogenes or tumor suppressors, playing crucial role not only in tumorigenesis, but also in tumor invasion and metastasis. miR-26a and transcription factor 12 (TCF12) have been reported to be involved in carcinogenesis, but the regulatory role of miR-26a/TCF12 in OC remains unknown. The aim of the present study was to investigate the expression profiles of TCF12 and miR-26a in OC patients and the correlation between TCF12 and miR-26a expression, and to demonstrate the effects of miR-26a binding on TCF12, to further reveal the miR-26a/TCF12 regulatory effects on the proliferation, migration, invasion and apoptosis in OC cells. In the present study, the expression of miR-26a was found to be low, while TCF12 was highly expressed in OC patient tissues and cell lines, and low miR-26a expression was statistically significantly correlated with high TCF12 expression. To the best of our knowledge, the present study was the first to demonstrate that TCF12 is a direct target of miR-26a, and upregulation of miR-26a resulted in TCF12 inhibition in OC cells. Furthermore, the proliferation, migration and invasion were inhibited and apoptosis was induced by miR-26a upregulation in OC cells. These results indicated that miR-26a may act as a tumor suppressor in OC, and TCF12 targeting by miR-26a may be a new therapeutic strategy for OC.
\end{abstract}

\section{Introduction}

Epithelial ovarian cancer (OC) is the most common gynecological tumor with a high mortality rate worldwide (1).

Correspondence to: Professor Yuquan Zhang, Department of Obstetrics and Gynecology, Affiliated Hospital of Nantong University, 20 Xisi Road, Nantong, Jiangsu 226001, P.R. China E-mail: jsntzhangyq@163.com

${ }^{*}$ Contributed equally

Key words: ovarian cancer, microRNA-26a, transcription factor 12, proliferation, migration, invasion, apoptosis
Epithelial OC is associated with a high rate of metastasis at an early stage, and metastasis is the major cause of the dismal prognosis (2); however, the detailed mechanisms underlying the propensity of OC for metastasis remain unclear. There is an urgent need to identify methods for early diagnosis and effective treatment for $\mathrm{OC}$.

MicroRNAs (miRNAs) are an endogenous class of single-stranded small RNAs 20-24 nucleotides in length, which play a variety of important regulatory roles in cells (3). The first miRNA was identified in Caenorhabditis elegans (4), whereas hundreds of miRNAs have been identified to date and found to be highly conserved in all types of organisms (5). In recent years, research on miRNAs has markedly progressed; in particular, the mechanism of target gene regulation, and numerous miRNAs and their target genes have been identified and investigated. miRNAs are promising targets for the diagnosis and treatment of diseases caused by multiple factors, particularly cancer (6), and they have also been studied in the context of OC (7). miR-26a has been reported to act as a tumor suppressor in numerous human cancers, such as prostate cancer (8-10), lung cancer (11-13), thyroid cancer (14), breast cancer (15-17), bladder cancer (18), hepatocellular carcinoma (19-21), colorectal cancer $(22,23)$, glioblastoma (24), melanoma (25) and esophageal squamous cell carcinoma (26). However, there are few reports of the role of transcription factor 12 (TCF12) in OC.

As a transcription factor, TCF12 belongs to the basic helix-loop-helix (bHLH) E protein family, which can recognize the E-box sequence CANNTG (27). TCF12 has been proven to be a regulator of cell development and differentiation (28), and has been demonstrated to be highly expressed in several human cancers (29-31). However, the role of TCF12 and the association of miR-26a and TCF12 expression in OC have not been extensively investigated to date.

The aim of the present study was to investigate the expressions of miR-26a and TCF12 and their correlation in OC patients. In addition, the regulatory effect of miR-26a on TCF12 expression was determined, and the proliferation, migration, invasion and apoptosis of OC cells were also investigated.

\section{Materials and methods}

Clinical patient samples and cell lines. A total of 27 cases of human fresh OC tissues and paired normal ovarian tissues 
were collected from patients (mean age 55.10 \pm 11.10 years, range 35-78 years) who were diagnosed with primary OC and underwent initial surgery at the Department of Obstetrics and Gynecology of the Affiliated Hospital of Nantong University. Written informed consent was obtained from all the patients and the study protocol was approved by the Ethics Committee of the Affiliated Hospital of Nantong University.

The human OC cell lines SK-OV-3 and A2780, the normal ovarian epithelial cell line IOSE80 and 293 cells were cultured in Dulbecco's modified Eagle's medium (DMEM; Thermo Fisher Scientific, Inc.) and supplemented with $10 \%$ fetal bovine serum (FBS; Thermo Fisher Scientific, Inc.) at $37^{\circ} \mathrm{C}$ in a humidified incubator with $5 \% \mathrm{CO}_{2}$.

Oligos, plasmids and transfection. The human miR-26a mimic (sense: 5'-UUCAAGUAAUCCAGGAUAGGCU-3', antisense: 5'-AGCCUAUCCUGGAUUACUUGAA-3') was used to regulate the expression of TCF12 in OC cells and a scrambled miR-26a mimic sequence used as negative control (NC; sense: 5'-GGUCGUCUGAUAUACGAUACA A-3'; antisense: 5'-UUGUAUCGUAUAUCAGACGACC-3'). The miR-26a binding site of TCF12 was predicted using TargetScan online software (http://www.targetscan.org/). The 50 base pairs (bp) cDNA of the $3^{\prime}$ untranslated region (UTR) sequence containing miR-26a-binding sites from TCF12 mRNA was cloned into a pGL3-control vector (Promega Corporation) downstream of the luciferase gene, which was used as the wild-type TCF12 (wtTCF12) plasmid. A point mutant miR-26a-binding site of TCF12 was constructed and was used as the mutant TCF12 (muTCF12) plasmid. Cell transfection of $50 \mathrm{pmol}$ miRNA or $80 \mathrm{ng}$ plasmid was performed by Lipofectamine ${ }^{\circledR} 2000$ transfection reagent (Thermo Fisher Scientific, Inc.) according to the manufacturer's instructions. miRNA, NC and DNA oligos were obtained from Biomics Biotechnologies Co., Ltd.

Reverse transcription-quantitative PCR (RT-qPCR) analysis. Small RNAs were isolated from tissues and cell lines using the mirVana miRNA Isolation Kit (Thermo Fisher Scientific, Inc.) according to the manufacturer's instructions, and the miR-26a expression levels were detected by the stem-loop RT-qPCR method (32). U6 small RNA was used as an internal control. Total RNA was extracted from cells using TRIzol ${ }^{\circledR}$ reagent (Thermo Fisher Scientific, Inc.) and RT-qPCR reactions were carried out using the One-Step RT-qPCR kit (Thermo Fisher Scientific, Inc.) according to the manufacturers' instructions. The thermocycling conditions were as follows: Pre-denaturation at $95^{\circ} \mathrm{C}$ for $10 \mathrm{~min}$, followed by 40 cycles of denaturation at $95^{\circ} \mathrm{C}$ for $20 \mathrm{sec}$, annealing at $58^{\circ} \mathrm{C}$ for $20 \mathrm{sec}$ and extension at $72^{\circ} \mathrm{C}$ for $30 \mathrm{sec}$. $\beta$-actin was used as an internal control. miRNA and mRNA level were analyzed by the $2^{-\Delta \Delta \mathrm{Cq}}$ method (33). The primer sequences were as follows: TCF12 forward: 5'-CTAATGAAGATGAGGATT-3' and reverse: 5'-GATGAAGAATAAGGAGTT-3'; $\beta$-actin forward: 5'-TTGCCGACAGGATGCAGAAGGA-3' and reverse: 5'-AGGTGGACAGCGAGGCCAGGAT-3'; miR-26a forward: 5'-GCGTTGTCTGGAATGTAAGG-3' and reverse: 5'-TGACGAGTTTAGAGCCGGATAG-3'; and U6 forward: 5'-AACGCTTCACGAATTTGCGT-3' and reverse: 5'-CTC GCTTCGGCAGCACA-3'.
Dual luciferase reporter assay. The 293 cells were used to measure luciferase activity. Briefly, 293 cells were plated into 24-well plates at $1 \times 10^{5}$ per well and cultured for $24 \mathrm{~h}$. Subsequently, $80 \mathrm{ng}$ wtTCF12 or muTCF12 plasmid and $50 \mathrm{nmol} / \mathrm{l} \mathrm{miR}-26 \mathrm{a}$ mimic or NC were co-transfected into 293 cells using Lipofectamine ${ }^{\circledR} 2000$ transfection reagent (Thermo Fisher Scientific, Inc.) along with pRL-TK plasmid (Promega Corporation). Cells were collected $48 \mathrm{~h}$ after transfection and firefly and Renilla luciferase activities were measured using a dual luciferase reporter assay system according to the manufacturer's instructions (Promega Corporation). The results of firefly luciferase activity were normalized to the Renilla luciferase activity.

Western blot analysis. Briefly, following treatment for $48 \mathrm{~h}$ as described above, SK-OV-3 and A2780 cells were collected, and total protein was extracted with RIPA lysis and extraction buffer (Thermo Fisher Scientific, Inc.). Total proteins were quantified using the BCA method, then separated by $10 \%$ SDS-PAGE with $50 \mu \mathrm{g}$ per lane and transferred onto a PVDF membrane (GEHealthcare). Subsequently, afterblocking with $5 \%$ non-fat dry milk for $2 \mathrm{~h}$ at room temperature, the membrane was incubated with rabbit anti-human TCF12 antibody (1:500 dilution, cat no. ab245540) or mouse anti-human $\beta$-actin antibody (1:1,000 dilution, cat no. ab179467) at $4^{\circ} \mathrm{C}$ overnight. After washing with TBST with $0.1 \%$ Tween-20, the PVDF membrane was incubated with a horseradish peroxidase-conjugated IgG (1:2,000 dilution, cat no. ab205718) for $2 \mathrm{~h}$ at room temperature; all antibodies were from Abcam, Inc. Finally, the specific proteins were detected using Pierce ECL Western Blotting Substrate (Thermo Fisher Scientific, Inc.), and ImageJ software 1.51 (National Institutes of Health) was used for densitometry analysis.

Cell proliferation assay. Cell proliferation was detected using the MTT method. In brief, $1.5 \times 10^{3}$ cells per well were grown in 96-well plates overnight, and then the cells were treated as indicated above. At 24, 48 and $72 \mathrm{~h}$ after treatment, $10 \mu \mathrm{l} \mathrm{MTT}$ solution (Promega Corporation) were added to each well. At $4 \mathrm{~h}$ after incubation at $37^{\circ} \mathrm{C}$ protected from light, $150 \mu \mathrm{l}$ DMSO were added to each well and incubated at $37^{\circ} \mathrm{C}$ for $10 \mathrm{~min}$. Finally, the OD value of each well was measured using a microplate reader at $490 \mathrm{~nm}$.

Transwell assay. Transwell assay was used to evaluate cell migration and Matrigel-based Transwell assay was used to evaluate cell invasion. The cells were plated onto 6-well plates and cultured for $24 \mathrm{~h}$. After treatment for $48 \mathrm{~h}$, as indicated above, cells were collected and suspended in DMEM at a density of $1 \times 10^{6}$ cells $/ \mathrm{ml}$. Prior to treatment, Transwell chambers $(8-\mu \mathrm{m}$ pore size; Corning, Inc.) were incubated with DMEM for $1 \mathrm{~h}$ at $37^{\circ} \mathrm{C}$. For cell invasion detection, Matrigel (BD Biosciences) was thawed at $4^{\circ} \mathrm{C}$ overnight, and $100 \mu 1$ (1:8 diluted in DMEM) were added into the Transwell upper chamber and incubated at $37^{\circ} \mathrm{C}$ for $1 \mathrm{~h}$. Cell suspension $(100 \mu \mathrm{l})$ was added into the upper chamber and $600 \mu \mathrm{l}$ DMEM supplemented with $10 \%$ FBS was added into the lower chamber. Following incubation for $24 \mathrm{~h}$ at $37^{\circ} \mathrm{C}$, the cells on upper surface of the membrane were carefully removed using a cotton swab, and the cells on the lower surface were fixed 
in $10 \%$ formaldehyde for $20 \mathrm{~min}$ at room temperature. After washing with PBS, the cells were stained in $0.5 \%$ crystal violet solution for $10 \mathrm{~min}$ at room temperature and washed with PBS. Finally, the stained cells on the lower surface of upper chamber were observed under a light microscope (magnification, x100).

Cell apoptosis assay. Annexin V-FITC and propidium iodide (PI) double staining followed by flow cytometry was used to evaluate cell apoptosis. Briefly, after treatment for $48 \mathrm{~h}$ as described above, $1 \times 10^{5}$ SK-OV-3 or A2780 cells were collected and washed with PBS, then transferred into centrifuge tubes and centrifuged at $800 \mathrm{x} \mathrm{g}$ for $5 \mathrm{~min}$ at $4^{\circ} \mathrm{C}$. After washing with PBS, the cells were re-suspended in $195 \mu 11 \mathrm{X}$ Annexin V-FITC binding buffer and $5 \mu \mathrm{l}$ Annexin V-FITC (Sigma-Aldrich; Merck KGaA) and incubated for $10 \mathrm{~min}$ at room temperature in the dark. Following centrifugation for $5 \mathrm{~min}$ at $800 \mathrm{x} \mathrm{g}$ at $4^{\circ} \mathrm{C}$, the cells were re-suspended in $190 \mu 1 \mathrm{1X}$ Annexin V-FITC binding buffer followed by $10 \mu 1$ PI (Sigma-Aldrich; Merck KGaA). Finally, cell apoptosis was detected using a flow cytometer (FACSCalibur; $\mathrm{BD}$ Biosciences) and the results were analyzed by $\mathrm{BD}$ CellQuest software, version 5.1 (BD Biosciences).

Statistical analysis. All data are presented as mean \pm standard deviation. Statistical analyses were performed using SPSS 20.0 software (IBM Corp.). Differences between two groups were tested by paired Student's two-tailed t-test. One-way ANOVA followed by Dunnett's post hoc test was used to compare multiple groups. The correlation of miR-26a with TCF12 expression was analyzed by Spearman's correlation analysis. $\mathrm{P}<0.05$ was considered to indicate statistically significant differences.

\section{Results}

Low miR-26a and high TCF12 expression is observed in OC patients. To investigate the expression of miR-26a and TCF12 in OC patients, 27 cases of fresh OC samples and paired normal ovarian tissues were used for RT-qPCR analysis. The results demonstrated that the miR-26a expression levels were low in OC tissues, while the TCF12 expression levels were high, compared with those in normal ovarian tissues $(\mathrm{P}<0.05$; Fig. 1A and B). Spearman's correlation analysis revealed that miR-26a was negatively correlated with TCF12 expression $(\mathrm{r}=-0.695, \mathrm{P}<0.05$; Fig. 1C).

miR-26a directly targets the 3'UTR region of TCF12 $m R N A$. As predicted by software, TCF12 mRNA contains a miR-26a-binding site at position 124 in the 3'UTR region. The luciferase reporter plasmids wtTCF12 and muTCF12 were constructed (Fig. 2A) and co-transfection of wtTCF12 or muTCF12 plasmid and miR-26a mimic into 293 cells was performed. Following transfection for $48 \mathrm{~h}$, the luciferase activity of wtTCF12 and miR-26a co-transfected cells was obviously decreased compared with that in cells co-transfected with NC and wtTCF12 or muTCF12 (P<0.05; Fig. 2B).

miR-26a inhibits the expression of TCF12 in OC cells. Furthermore, the miR-26a expression levels were found to be low in the OC cell lines SK-OV-3 and A2780, while the
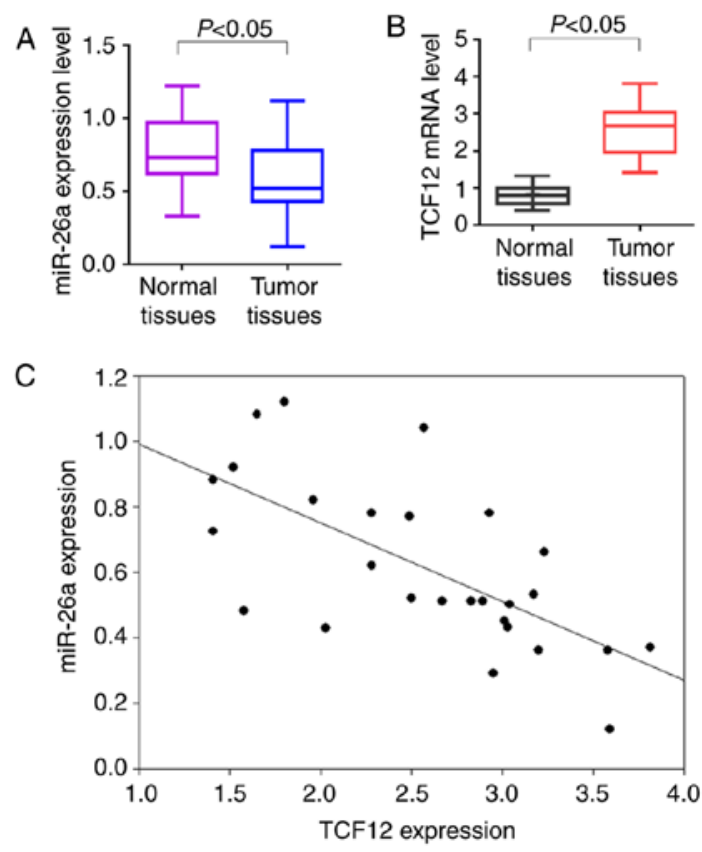

Figure 1. miR-26a and TCF12 expression in OC and paired normal ovarian tissues. (A) miR-26a levels in 27 cases of OC tissues and paired normal ovarian tissues were detected by stem-loop RT-qPCR; (B) The expression levels of TCF12 in 27 cases of OC tissues and paired normal ovarian tissues were detected by RT-qPCR; (C) Correlation of miR-26a and TCF12 levels in OC patients. OC, ovarian cancer, TCF12, transcription factor 12; RT-qPCR, reverse transcription-quantitative PCR.

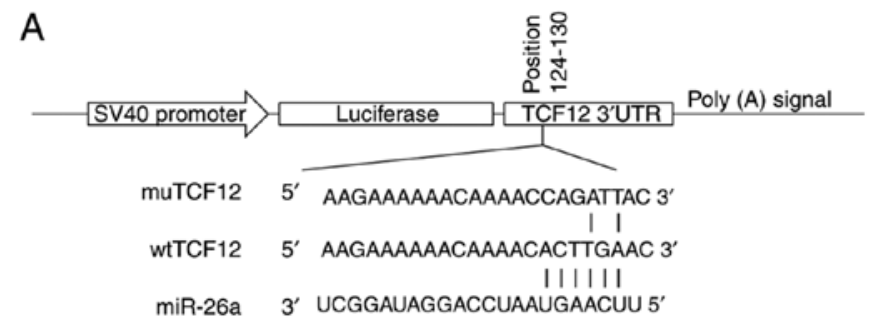

B

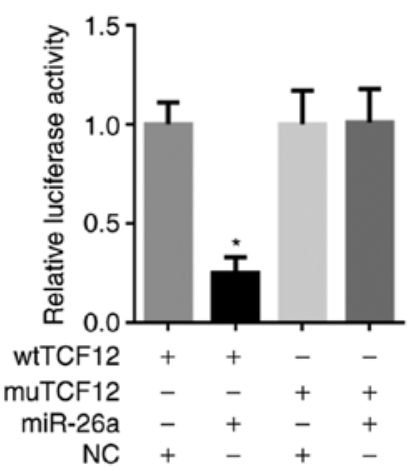

Figure 2. The regulatory effect of miR-26a on the expression of TCF12 was detected by dual luciferase reporter assay. (A) The miR-26a-binding site of TCF12 and the constructed reporter plasmids. (B) The relative luciferase activity was detected by the dual luciferase reporter assay. ${ }^{*} \mathrm{P}<0.05$ compared with muTCF12 and pGL3 control-treated cells. TCF12, transcription factor 12; NC, negative control; UTR, untranslated region; wt, wild-type; mu, mutant type.

TCF12 expression levels were high, compared with those in IOSE80 cells ( $\mathrm{P}<0.05$; Fig. $3 \mathrm{~A}$ and $\mathrm{B})$. To further observe regulation of TCF12 expression by miR-26a in OC cells, human 
A

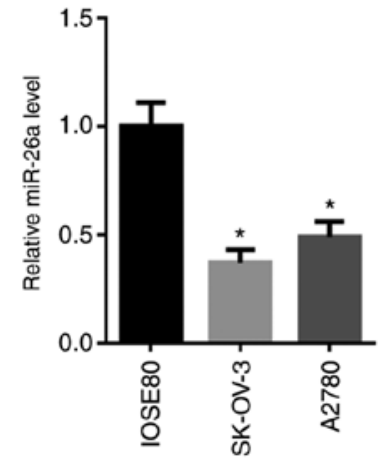

B

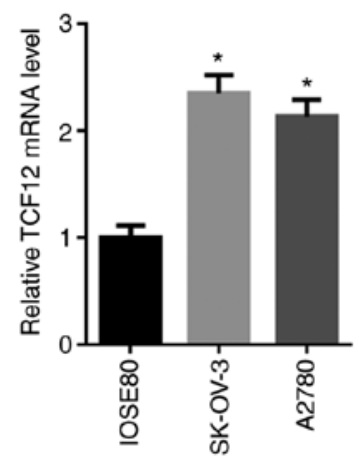

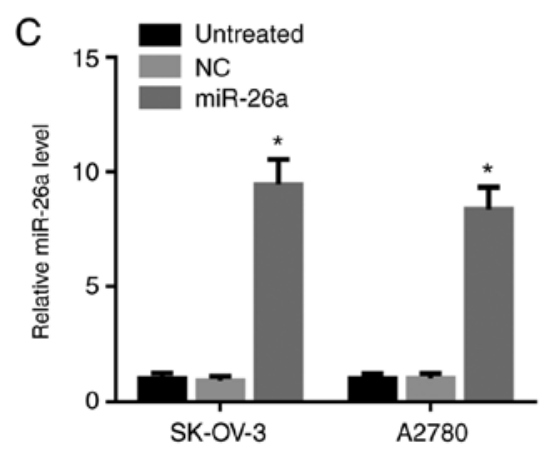
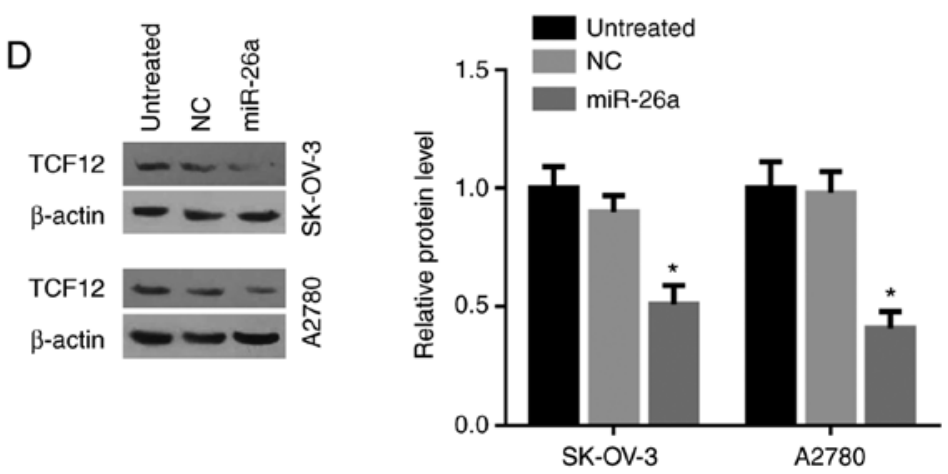

Figure 3. miR-26a and TCF12 expression levels and their interaction in OC cells. (A) miR-26a levels in the SK-OV-3 and A2780 OC cells and in the normal ovarian cell line IOSE80. (B) TCF12 mRNA levels in SK-OV-3, A2780 and IOSE80 cells. "P<0.05 compared with IOSE80 cells. (C) miR-26a levels in SK-OV-3 and A2780 OC cells with miR-26a mimic transfection, "P<0.05 compared with NC-treated or untreated cells. (D) The protein expression of TCF12 was inhibited by miR-26a. "P $<0.05$ compared with NC-treated or untreated cells. OC, ovarian cancer; TCF12, transcription factor 12; NC, negative control.

A

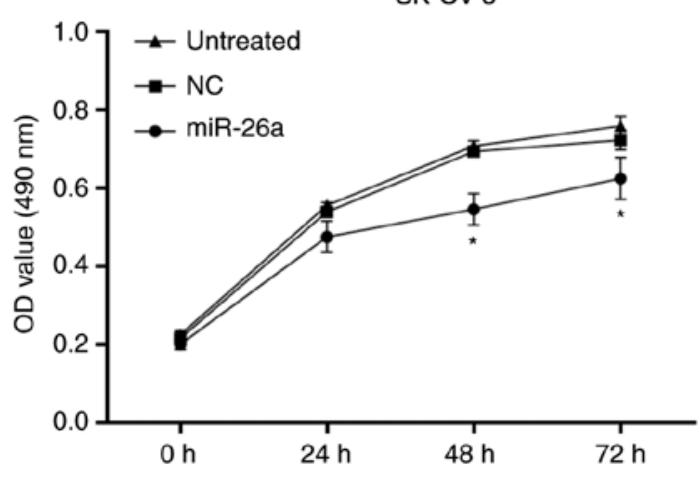

B

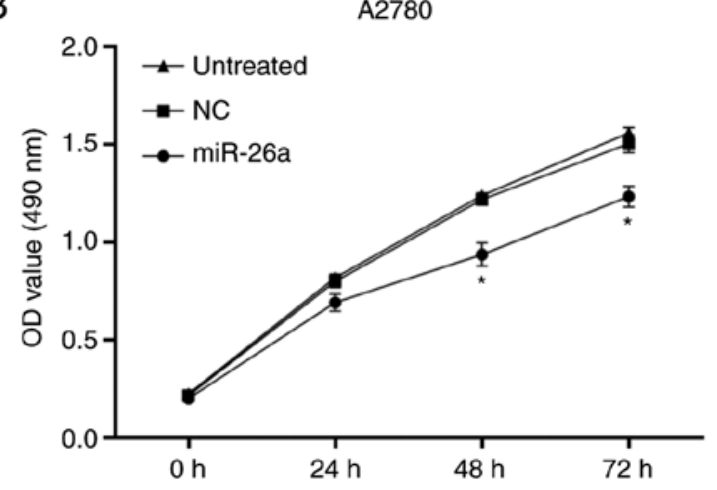

Figure 4. Effects of TCF12 inhibited by miR-26a on OC cell proliferation. (A) SK-OV-3 cell proliferation was inhibited by miR-26a; (B) A2780 cell proliferation was inhibited by miR-26a. " $\mathrm{P}<0.05$ compared with NC or untreated cells. TCF12, transcription factor 12; NC, negative control; OD, optical density.

miR-26a mimic was used to increase endogenous miR-26a in OC cells, and the miR-26a levels in SK-OV-3 and A2780 cells were significantly upregulated following miR-26a mimic transfection (Fig. 3C). The protein expression of TCF12 was significantly inhibited by miR-26a in both SK-OV-3 and A2780 cells, compared with NC-treated or untreated cells (P<0.05; Fig. 3D).

miR-26a inhibits the proliferation of OC cells. MTT assay was used to investigate the inhibitory effects of miR-26a on OC cell growth. TCF12 inhibition by miR-26a clearly inhibited the growth of SK-OV-3 (Fig. 4A) and A2780 (Fig. 4B) cells at 48 and $72 \mathrm{~h}$, compared with NC-treated or untreated cells $(\mathrm{P}<0.05)$.
miR-26a inhibits the migration and invasion of $O C$ cells. Transwell and Matrigel-based Transwell assay was used to evaluate the inhibitory effects of miR-26a on OC cell migration and invasion, respectively. The results demonstrated that miR-26a treatment significantly decreased SK-OV-3 and A2780 cell migration and invasion, compared with NC-treated or untreated cells ( $\mathrm{P}<0.05$; Fig. 5A and $\mathrm{B})$.

miR-26a induces the apoptosis of OC cells. Annexin-VFITC/PI flow cytometry was used to evaluate the effects of miR-26a on OC cell apoptosis. Treatment with miR-26a for $48 \mathrm{~h}$ significantly increased apoptosis of both SK-OV-3 and A2780 cells compared with cells treated with $\mathrm{NC}(\mathrm{P}<0.05$; Fig. 5C). 
A

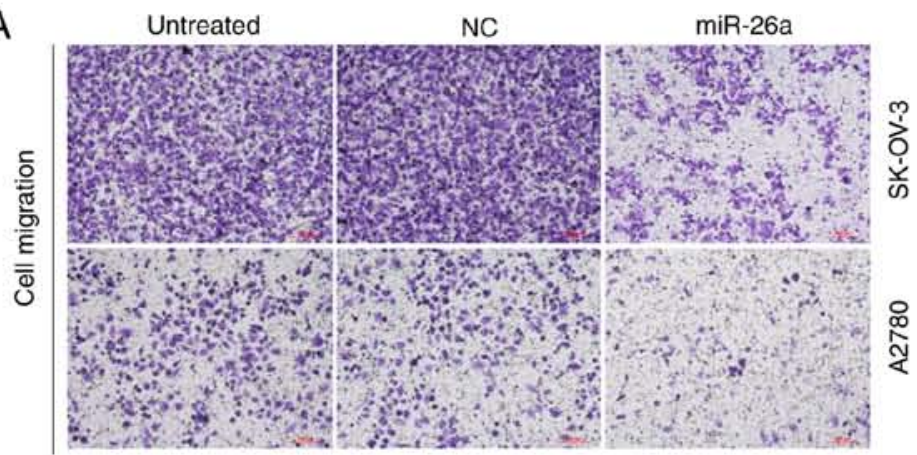

B

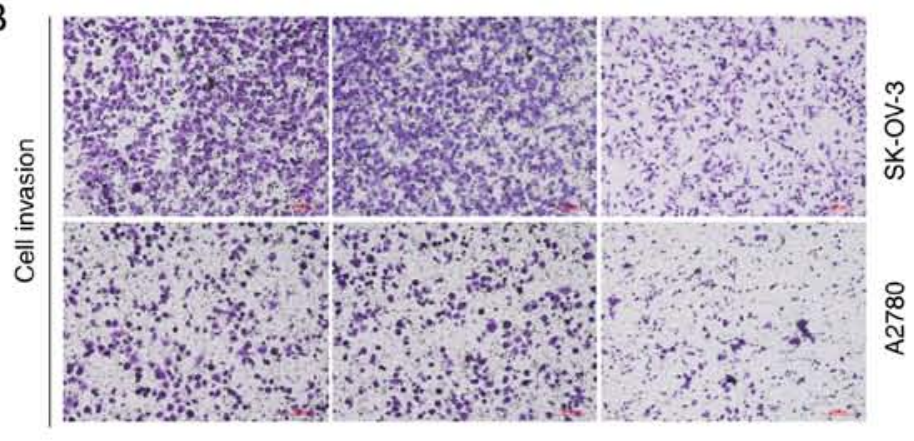

C
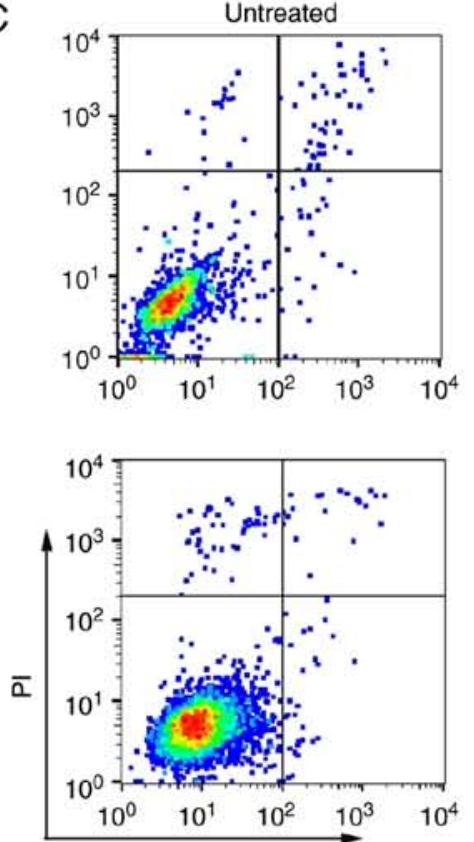
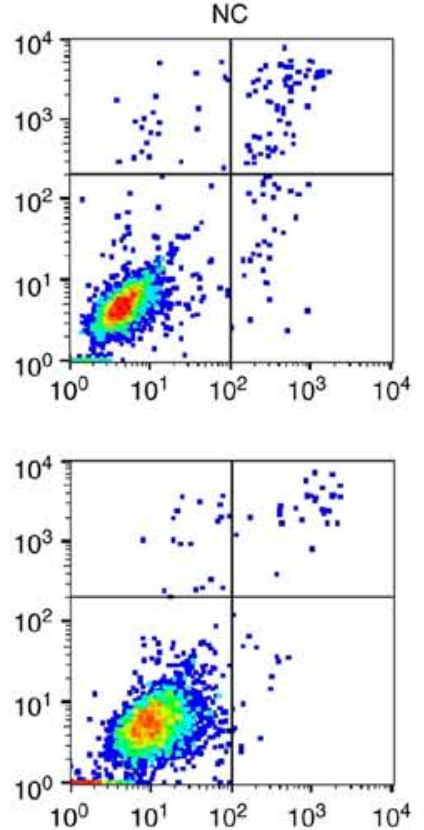
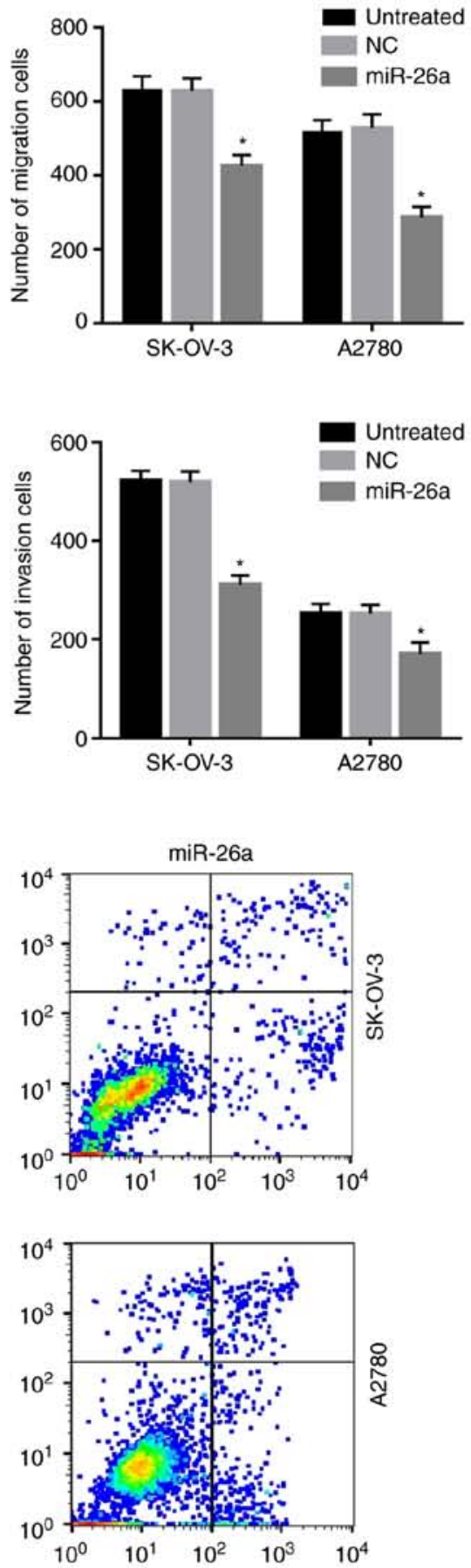

Annexin V-FITC

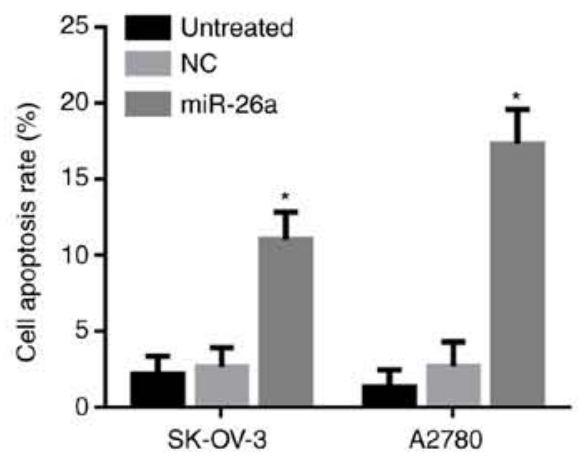

Figure 5. Effects of TCF12 inhibited by miR-26a on OC cell migration, invasion and apoptosis. (A) The migration of SK-OV-3 and A2780 cells was inhibited by miR-26a; (B) the invasion of SK-OV-3 and A2780 cells was inhibited by miR-26a; (C) apoptosis of SK-OV-3 and A2780 cells was induced by miR-26a. "P<0.05 compared with NC or untreated cells. TCF12, transcription factor 12; FITC, fluorescein isothiocyanate; PI, propidium iodide; NC, negative control. Scale bar, $100 \mu \mathrm{m}$. 


\section{Discussion}

Lack of early diagnosis and effective treatment is a major cause of death from OC among women with malignant gynecological tumors (2). Individualized cancer treatment based on molecular targeted therapy is crucial for improving therapeutic efficacy, and molecules that are heavily involved in the uncontrolled cell growth and proliferation, inhibition of apoptosis and tumor metastasis may represent promising targets for cancer therapy (34).

miRNAs are small endogenously expressed RNAs in mammalian cells, which have been used in regulation of gene expression at the post-transcriptional level in a sequence-specific manner (35). miRNAs have been demonstrated to play multiple functional roles in biological processes, such as cell developmental control, regulation, and the occurrence of various diseases, particularly cancer, due to their high abundance, sequence conservation and tissue specificity (5). Due to their different expression patterns and functions, miRNAs involved in tumorigenesis may be classified as oncogenes or tumor suppressors in different human cancers (36); thus, miRNAs may be used as novel targets or markers for detection, prognosis, diagnosis and therapy (37). In recent years, a number of studies have identified aberrant expression of miRNAs in ovarian tumorigenesis leading to OC (38). miR-26a was identified as a tumor suppressor in a number of human cancers. miR-26a was shown to exert an antiproliferative effect on prostate cancer cells by decreasing survival and migration and inducing cell cycle arrest and apoptosis (9). In gastric cancer, miR-26a promoted cell proliferation, migration and invasion, and phosphatase and tensin homolog was identified as a direct target of miR-26a (10). miR-26a was demonstrated to enhance the metastatic potential of lung cancer cells by targeting glycogen synthase kinase (GSK) $3 \beta$ of the $\beta$-catenin pathway; miR-26a expression was found to be negatively correlated with GSK $3 \beta$ expression in patients with lung cancer, and overexpression of GSK3 $\beta$ reversed the enhancing effect of miR-26a on lung cancer cell migration and invasion. In addition, integrin $\beta 8$ (13), lin-28 homolog B (39) and matrix metalloproteinase-2 (11) have also been identified as targets in lung cancer. miR-26a has been proven to be associated with metastasis, survival and apoptosis in breast cancer, acts as a tumor suppressor and serves as a prognostic marker $(15,16)$. The proliferation, migration and invasion of hepatocellular carcinoma (HCC) cells can also be inhibited by miR-26a by targeting diverse genes and pathways, such as the epithelial-to-mesenchymal transition (40), interleukin-6-Stat3 (13) and PI3K/Akt (23) pathways, and low miR-26a levels were found to be closely associated with metastasis and progression of HCC (19-21). In bladder cancer (18), colorectal cancer (23) and melanoma (25), miR-26a was found to play the same functional roles. In recent years, the expression of miR-26a has been reported to be low in OC tissues and cells, further investigation demonstrated that the proliferation of OC cells was inhibited while their apoptosis was induced by miR-26a, suggesting that miR-26a downregulation may be predictive of poor prognosis in epithelial OC $(41,42)$. Moreover, TCF12 was found to be highly expressed in OC patients in our recent study (43), and its overexpression was correlated with histological grade and metastasis of OC, whereas TCF12 downregulation inhibited the growth, migration and invasion of OC cells and promoted apoptosis. In the present study, the expression of miR-26a was also found to be low in OC patients and cell lines, whereas the expression of TCF12 was high, and low miR-26a expression was statistically significantly correlated with high TCF12 expression. To the best of our knowledge, the present study was the first to demonstrate that TCF12 is a direct target of miR-26a by the dual luciferase reporter assay. The expression of TCF12 in OC cells was inhibited by miR-26a at both the mRNA and protein levels. Furthermore, the proliferation, migration and invasion of SK-OV-3 and A2780 cells were inhibited by miR-26a through suppression of TCF12, whereas apoptosis was induced.

Therefore, the findings of the present study suggest that upregulation of miR-26a may inhibit metastasis and promote apoptosis in OC cells by targeting TCF12, which may be a potential strategy for OC treatment.

\section{Acknowledgements}

Not applicable.

\section{Funding}

The present study was supported by a grant from the Science Foundation of Nantong City, Jiangsu Province, China (no. MS12017008-2).

\section{Availability of data and materials}

The datasets generated and analyzed during the present study are available from the corresponding author upon reasonable request.

\section{Authors' contributions}

SG, TB and YZ contributed to conception and design of this study; YL and TB collected the clinical samples and patient information; SG, TB, MS and YL performed the experiments; SG, TB, MS, YL and YZ acquired, analyzed and interpreted the data; SG was a major contributor to drafting and writing the manuscript; TB, MS, YL and YZ revised the manuscript. All authors have read and approved the final version of the manuscript for publication.

\section{Ethics approval and consent to participate}

Written informed consent was obtained from all the patients and the study protocol was approved by the Ethics Committee of the Affiliated Hospital of Nantong University.

\section{Patient consent for publication}

Not applicable.

\section{Competing interests}

The authors declare that they have no competing interests. 


\section{References}

1. Vetter MH and Hays JL: Use of targeted therapeutics in epithelial ovarian cancer: A review of current literature and future directions. Clin Ther 40: 361-371, 2018.

2. Morris CR, Sands MT and Smith LH: Ovarian cancer: Predictors of early-stage diagnosis. Cancer Causes Control 21: 1203-1211, 2010.

3. Mallory AC and Bouché N: MicroRNA-directed regulation: To cleave or not to cleave. Trends Plant Sci 13: 359-367, 2008.

4. Lee RC, Feinbaum RL and Ambros V: The C. elegans heterochronic gene lin-4 encodes small RNAs with antisense complementarity to lin-14. Cell 75: 843-854, 1993.

5. Chen K and Rajewsky N: The evolution of gene regulation by transcription factors and microRNAs. Nat Rev Genet 8: 93-103, 2007.

6. Bell E and Taylor MA: Functional roles for exosomal microRNAs in the tumour microenvironment. Comput Struct Biotechnol J 15: 8-13, 2016.

7. Mahdian-Shakib A, Dorostkar R, Tat M, Hashemzadeh MS and Saidi N: Differential role of microRNAs in prognosis, diagnosis, and therapy of ovarian cancer. Biomed Pharmacother 84: 592-600, 2016

8. Erdmann K, Kaulke K, Rieger C, Salomo K, Wirth MP and Fuessel S: miR-26a and miR-138 block the G1/S transition by targeting the cell cycle regulating network in prostate cancer cells. J Cancer Res Clin Oncol 142: 2249-2261, 2016.

9. Rizzo M, Berti G, Russo F, Fazio S, Evangelista M, D'Aurizio R, Pellegrini M and Rainaldi G: Discovering the miR-26a-5p targetome in prostate cancer cells. J Cancer 8: 2729-2739, 2017.

10. Ding K, Wu Z, Wang N, Wang X, Wang Y, Qian P, Meng G and Tan S: miR-26a performs converse roles in proliferation and metastasis of different gastric cancer cells via regulating of PTEN expression. Pathol Res Pract 213: 467-475, 2017.

11. Pastuszak-Lewandoska D, Kordiak J, Czarnecka KH, Migdalska-Sęk M, Nawrot E, Domańska-Senderowska D, Kiszałkiewicz JM, Antczak A, Górski P and Brzeziańska-Lasota E: Expression analysis of three miRNAs, miR-26a, miR-29b and miR-519d, in relation to MMP-2 expression level in non-small cell lung cancer patients: A pilot study. Med Oncol 33: 96, 2016

12. Lin G, Liu B, Meng Z, Liu Y, Li X, Wu X, Zhou Q and Xu K: miR-26a enhances invasive capacity by suppressing GSK3 $\beta$ in human lung cancer cells. Exp Cell Res 352: 364-374, 2017.

13. Song Q, Liu B, Li X, Zhang Q, Cao L, Xu M, Meng Z, Wu X and $\mathrm{Xu} \mathrm{K}$ : miR-26a-5p potentiates metastasis of human lung cancer cells by regulating ITG $\beta 8$ - JAK2/STAT3 axis. Biochem Biophys Res Commun 501: 494-500, 2018.

14. Gong Y, Wu W, Zou X, Liu F, Wei T and Zhu J: miR-26a inhibits thyroid cancer cell proliferation by targeting ARPP19. Am J Cancer Res 8: 1030-1039, 2018

15. Liu P, Tang H, Chen B, He Z, Deng M, Wu M, Liu X, Yang L, Ye $\mathrm{F}$ and Xie $\mathrm{X}$ : miR-26a suppresses tumour proliferation and metastasis by targeting metadherin in triple negative breast cancer. Cancer Lett 357: 384-392, 2015.

16. Cabello P, Pineda B, Tormo E, Lluch A and Eroles P: The antitumor effect of metformin is mediated by miR-26a in breast cancer. Int J Mol Sci 17: 1298, 2016.

17. Zhao XX, Yuan QZ, Mu DP, Sun DW, Bo QA, Pan GZ, Li GQ, Cui T, Ding PP, You FP, et al: MicroRNA-26a inhibits proliferation by targeting high mobility group AT-hook 1 in breast cancer Int J Clin Exp Pathol 8: 368-373, 2015.

18. Lin Y, Chen H, Hu Z, Mao Y, Xu X, Zhu Y, Xu X, Wu J, Li S, Mao Q, et al: miR-26a inhibits proliferation and motility in bladder cancer by targeting HMGA1. FEBS Lett 587: 2467-2473, 2013.

19. Sun M,Zhao X, Liang L,Pan X,LvH and Zhao Y: Sialyltransferase ST3GAL6 mediates the effect of microRNA-26a on cell growth, migration, and invasion in hepatocellular carcinoma through the protein kinase $\mathrm{B} / \mathrm{mammalian}$ target of rapamycin pathway. Cancer Sci 108: 267-276, 2017.

20. Ma Y, Deng F, Li P, Chen G, Tao Y and Wang H: The tumor suppressive miR-26a regulation of FBXO11 inhibits proliferation, migration and invasion of hepatocellular carcinoma cells. Biomed Pharmacother 101: 648-655, 2018.

21. Gao XM, Zhu Y, Li JH, Wang XY,Zhang XF, Yi CH and Yang X: MicroRNA-26a induces a mitochondrial apoptosis mediated by p53 through targeting to inhibit Mcl1 in human hepatocellular carcinoma. Onco Targets Ther 11: 2227-2239, 2018.
22. Jinushi T, Shibayama Y, Kinoshita I, Oizumi S, Jinushi M, Aota T, Takahashi T, Horita S, Dosaka-Akita H and Iseki K: Low expression levels of microRNA-124-5p correlated with poor prognosis in colorectal cancer via targeting of SMC4. Cancer Med 3: 1544-1552, 2014.

23. Liu B, Pan S, Xiao Y, Liu Q, Xu J and Jia L: LINC01296/miR-26a/GALNT3 axis contributes to colorectal cancer progression by regulating O-glycosylated MUC1 via PI3K/AKT pathway. J Exp Clin Cancer Res 37: 316, 2018.

24. ParvizHamidi M, Haddad G, Ostadrahimi S, Ostadrahimi N, Sadeghi S, Fayaz S and Fard-Esfahani P: Circulating miR-26a and miR-21 as biomarkers for glioblastoma multiform. Biotechnol Appl Biochem 66: 261-265, 2019.

25. Gao J, Zeng K, Liu Y, Gao L and Liu L: LncRNA SNHG5 promotes growth and invasion in melanoma by regulating the miR-26a-5p/TRPC3 pathway. Onco Targets Ther 12: 169-179, 2018.

26. Chen Z, Zhao L, Zhao F, Yang G and Wang J: MicroRNA-26b regulates cancer proliferation migration and cell cycle transition by suppressing TRAF5 in esophageal squamous cell carcinoma. Am J Transl Res 8: 1957-1970, 2016.

27. Thorsen K, Schepeler T, Øster B, Rasmussen MH, Vang S, Wang K, Hansen KQ, Lamy P, Pedersen JS, Eller A, et al: Tumor-specific usage of alternative transcription start sites in colorectal cancer identified by genome-wide exon array analysis. BMC Genomics 12: 505, 2011.

28. L'Abbate A, Tolomeo D, De Astis F, Lonoce A, Lo Cunsolo C, Mühlematter D, Schoumans J, Vandenberghe P, Van Hoof A, Palumbo O, et al: $\mathrm{T}(15 ; 21)$ translocations leading to the concurrent downregulation of RUNX1 and its transcription factor partner genes SIN3A and TCF12 in myeloid disorders. Mol Cancer 14: 211, 2015.

29. Labreche K, Simeonova I, Kamoun A, Gleize V, Chubb D, Letouzé E, Riazalhosseini Y, Dobbins SE, Elarouci N, Ducray F, et al: TCF12 is mutated in anaplastic oligodendroglioma. Nat Commun 6: 7207, 2015.

30. Tang X, Hou Y, Yang G, Wang X, Tang S, Du YE, Yang L, Yu T, Zhang H, Zhou M, et al: Stromal miR-200s contribute to breast cancer cell invasion through CAF activation and ECM remodeling. Cell Death Differ 23: 132-145, 2016.

31. Chen YF, Yang CC, Kao SY, Liu CJ, Lin SC and Chang KW: MicroRNA-211 enhances the oncogenicity of carcinogen-induced oral carcinoma by repressing TCF12 and increasing antioxidant activity. Cancer Res 76: 4872-4886, 2016.

32. Chen C, Ridzon DA, Broomer AJ, Zhou Z, Lee DH, Nguyen JT, Barbisin M, Xu NL, Mahuvakar VR, Andersen MR, et al: Real-time quantification of microRNAs by stem-loop RT-PCR. Nucleic Acids Res 33: e179, 2005.

33. Livak KJ and Schmittgen TD: Analysis of relative gene expression data using real-time quantitative PCR and the 2(-Delta Delta C(T)) method. Methods 25: 402-408, 2001.

34. Hertz DL and McLeod HL: Integrated patient and tumor genetic testing for individualized cancer therapy. Clin Pharmacol Ther 99: 143-146, 2016.

35. Ichimura A, Ruike Y, Terasawa K and Tsujimoto G: miRNAs and regulation of cell signaling. FEBS J 278: 1610-1618, 2011.

36. Svoronos AA, Engelman DM and Slack FJ: OncomiR or tumor suppressor? The duplicity of microRNAs in cancer. Cancer Res 76: 3666-3670, 2016.

37. Moles R: MicroRNAs-based therapy: A novel and promising strategy for cancer treatment. Microrna 6: 102-109, 2017.

38. Deb B, Uddin A and Chakraborty S: miRNAs and ovarian cancer: An overview. J Cell Physiol 233: 3846-3854, 2018

39. Lu YY, Lin Y, Ding DX, Su S, Chi QQ, Zhang YC, Sun J, Zhang X, Zhu HM, Huang QS, et al: miR-26a functions as a tumor suppressor in ambient particulate matter-bound metal-triggered lung cancer cell metastasis by targeting LIN28B-IL6-STAT3 axis. Arch Toxicol 92: 1023-1035, 2018

40. Chang L, Li K and Guo T: miR-26a-5p suppresses tumor metastasis by regulating EMT and is associated with prognosis in HCC. Clin Transl Oncol 19: 695-703, 2017.

41. Sun TY, Xie HJ, He H, Li Z and Kong LF: miR-26a inhibits the proliferation of ovarian cancer cells via regulating CDC6 expression. Am J Transl Res 8: 1037-1046, 2016.

42. De Lima AB, Silva LM, Gonçales NG, Carvalho MRS, da Silva Filho AL and da Conceição Braga L: Three-dimensional cellular arrangement in epithelial ovarian cancer cell lines TOV-21G and SKOV-3 is associated with apoptosis-related miRNA expression modulation. Cancer Microenviron 11: 85-92, 2018.

43. Gao S, Bian T, Zhang Y, Su M and Liu Y: TCF12 overexpression as a poor prognostic factor in ovarian cancer. Pathol Res Pract 215: 152527, 2019 